\title{
Hypothalamic contents of LHRH and catecholamines during the ovulatory cycle of the hen (Gallus domesticus)
}

\author{
P. G. Knight, Susan C. Wilson, R. T. Gladwell and F. J. Cunningham
}

Department of Physiology \& Biochemistry, University of Reading, Whiteknights, Reading RG6 2AJ, U.K.

\begin{abstract}
Summary. Concentrations of LHRH, dopamine, noradrenaline and adrenaline in the anterior hypothalamus-preoptic region (AH-POR) and posterior hypothalamusmedian eminence ( $\mathrm{PH}$-me) were determined in hens killed at different times in relation to the first ovulation of a sequence. The occurrence of a preovulatory rise in plasma $\mathrm{LH}$ concentration 4-6h before the expected time of ovulation was confirmed. This rise in plasma LH was accompanied by a significant $(P<0.01) 50 \%$ reduction in the LHRH content of the AH-POR and $\mathrm{PH}$-me while the subsequent fall in plasma $\mathrm{LH}$ was accompanied by a restoration of the LHRH content of both regions to their former levels. Although no significant fluctuations in the hypothalamic content of either dopamine, noradrenaline or adrenaline were detected during the ovulatory cycle, significant correlations between LHRH content and catecholamine content were observed in the AH-POR $(P<0.05)$ and PH-me $(P<0.01)$. Thus mean levels of each amine followed the same temporal pattern as LHRH content with minimum values being observed shortly before the peak of the preovulatory surge of LH. These findings support the conclusion that an enhanced secretion of LHRH from the median eminence, possibly associated with an increased activity of catecholaminergic neurones, is a prerequisite for the preovulatory release of $\mathrm{LH}$ in the hen.
\end{abstract}

\section{Introduction}

Spontaneous ovulations in the laying hen are invariably preceded by a surge in the release of luteinizing hormone (LH) from the anterior pituitary gland (Furr, Bonney, England \& Cunningham, 1973; Wilson \& Sharp, 1973). Under standard photoperiodic conditions (e.g. $16 \mathrm{~h}$ light: $8 \mathrm{~h}$ darkness) preovulatory surges of $\mathrm{LH}$ are initiated only during an 8-10-h period which starts shortly after the onset of darkness and which has been termed the 'open period' (Fraps, 1965; Wilson \& Cunningham, 1980). Successive preovulatory surges of LH occur at a slightly later time each day until the surge of LH associated with the final ovulation of a sequence coincides with the end of the 'open period'. On the following day neither a preovulatory release of LH nor an ovulation occurs.

Whilst little is known about the neuroendocrine mechanisms which regulate this cyclic pattern of LH release from the anterior pituitary gland, there is good evidence that progesterone secreted by the mature ovarian follicle acts at the central neural level to promote an increased secretion of luteinizing hormone-releasing hormone (LHRH) into the hypophysial portal vasculature. Therefore, exogenous progesterone, when administered at an appropriate stage of the ovulatory cycle, can induce premature ovulation (Fraps \& Dury, 1943) and initiate release of LH (Wilson \& Sharp, 1975). The ability of progesterone to induce premature ovulation is dependent on the integrity of 
the anterior hypothalamus (Ralph \& Fraps, 1959). The observation that passive immunization of laying hens with antibodies raised against progesterone (Furr \& Smith, 1975) or LHRH (Fraser \& Sharp, 1978) inhibits ovulation further emphasizes the obligatory role of both progesterone and LHRH in the ovulatory process.

Whilst there is now overwhelming evidence in mammals that central catecholaminergic neurones terminating in the hypothalamus participate in the regulation of gonadotrophin secretion (see reviews by Weiner \& Ganong, 1978; Sawyer, 1979; Meites \& Sonntag, 1981), relatively few reports pertaining to the role of these putative neurotransmitters in the control of reproduction in birds have been published (see El Halawani, Burke \& Ogren, 1980; Buonomo, Rabii \& Scanes, 1981 ; Knight, Wilson, Gladwell \& Cunningham, 1982b). This paucity of information for birds on the possible functional interactions between hypothalamic catecholaminergic neurones and LHRH-producing neurones prompted us to determine whether any changes in the hypothalamic concentrations of $\mathrm{LHRH}$, dopamine, noradrenaline and adrenaline occur during the ovulatory cycle of the hen, and, if so, whether such changes could be temporally related to the preovulatory release of $\mathrm{LH}$.

\section{Materials and Methods}

Birds. Hens laying regular sequences of 6-12 eggs were selected from a flock of over 400 Rossbrown hens towards the end of their first year of lay. The 89 hens were individually caged and maintained under a lighting schedule of $16 \mathrm{~h}$ light $: 8 \mathrm{~h}$ darkness (lights on $02: 00 \mathrm{~h}$ ) with free access to food and water. Oviposition times for each hen were recorded automatically to the nearest minute for at least 2 weeks before starting the study. Groups of 12 hens were killed by decapitation at $10,6,2.5$ and $0.5 \mathrm{~h}$ before and at 7,12 and $16 \mathrm{~h}$ after the time at which each was expected to ovulate the first $(\mathrm{Cl})$ egg of a sequence. Immediately before death, blood $(1 \mathrm{ml})$ was withdrawn from a wing vein into heparinized tubes. Successive blood samples were withdrawn at 2-h intervals from a further 5 hens for a 24-h period starting $8 \mathrm{~h}$ before their $\mathrm{Cl}$ ovulations were expected. For hens maintained in this photoperiod it has previously been shown (Warren \& Scott, 1935; Wilson \& Cunningham, 1980) that $\mathrm{Cl}$ ovulations occur about $8 \mathrm{~h}$ after the onset of darkness, i.e. at about $02: 00 \mathrm{~h}$ in this study. Shortly after collection, blood was centrifuged for $10 \mathrm{~min}$ at $1500 \mathrm{~g}$ and the plasma was separated and stored at $-20^{\circ} \mathrm{C}$. Brains were removed within $2 \mathrm{~min}$ of death and immediately frozen on solid $\mathrm{CO}_{2}$. Two blocks of tissue were isolated from the ventral diencephalon using a razor blade: these were the anterior hypothalamic-preoptic region (AH-POR) and the posterior hypothalamus which included the entire median eminence ( $\mathrm{PH}-\mathrm{me}$ ). Posteriorly the AHPOR extended $4 \mathrm{~mm}$ from a plane $2 \mathrm{~mm}$ anterior to the rostral margin of the optic chiasma while the $\mathrm{PH}-$ me extended $4 \mathrm{~mm}$ from a plane immediately posterior to the $\mathrm{AH}-\mathrm{POR}$. Dorsally both the $\mathrm{AH}-\mathrm{POR}$ and $\mathrm{PH} / \mathrm{me}$ extended $3 \mathrm{~mm}$ from the ventral surface of the brain and their lateral limits were approximately $1.5 \mathrm{~mm}$ either side of the third ventricle. Tissue samples were weighed (AHPOR : $55.4 \pm 0.8 \mathrm{mg}, n=84 ; \mathrm{PH}-\mathrm{me}: 48.8 \pm 0.7 \mathrm{mg}, n=84$ ) and disrupted by sonication for 20 $\mathrm{sec}$ in $0.5 \mathrm{ml}$ chilled $0.05 \mathrm{M}-\mathrm{HCl}$. For LHRH determination a portion $(100 \mu \mathrm{l})$ of each sample was transferred to a clean tube containing $100 \mu \mathrm{l} 0.05 \mathrm{M}-\mathrm{NaOH}$ and $800 \mu \mathrm{l} 0.1 \mathrm{M}$-sodium phosphate buffer $\mathrm{pH} 7.5$ and heated at $95^{\circ} \mathrm{C}$ for $10 \mathrm{~min}$ to inactivate endogenous peptidases. Samples were stored at $-20^{\circ} \mathrm{C}$ until required for assay. Immediately before assay samples were thawed and centrifuged at $4^{\circ} \mathrm{C}$ for $30 \mathrm{~min}$ at $2000 \mathrm{~g}$. For catecholamine determination the remaining $400 \mu \mathrm{l}$ homogenate was deproteinized by adding $100 \mu \mathrm{l}$ chilled $1 \mathrm{M}$-perchloric acid. After centrifugation at $4^{\circ} \mathrm{C}$ for $30 \mathrm{~min}$ at $2000 \mathrm{~g}$ supernatants were decanted and stored at $-80^{\circ} \mathrm{C}$ until required.

Assay of $L H R H$. The LHRH content of tissue extracts was determined using the heterologous radioimmunoassay method previously described and validated for use in fowl (Knight, Cunningham \& Gladwell, 1983). Concentrations of LHRH were expressed in terms of a synthetic mammalian LHRH standard and the limit of detection of the assay was approximately $1 \mathrm{pg} / \mathrm{tube}$. 
All samples were assayed in duplicate at two dilutions in a single assay and the within-assay coefficient of variation was $9 \%$.

Assay of $\mathrm{LH}$. Concentrations of $\mathrm{LH}$ in plasma were determined using the homologous radioimmunoassay for chicken LH described by Follett, Scanes \& Cunningham (1972). All samples were included in a single assay and the within-assay coefficient of variation was $8 \%$. The limit of detection of the assay was $40 \mathrm{pg} /$ tube.

Assay of catecholamines. The concentrations of dopamine, noradrenaline and adrenaline were measured by reversed-phase high-performance liquid chromatography with electrochemical detection according to the method of Mefford, Gilberg \& Barchas (1980). Briefly, $100 \mu$ l portions of tissue extracts and external standards which consisted of mixtures of dopamine, noradrenaline and adrenaline in $0.2 \mathrm{M}$-perchloric acid at concentrations of between 5 and $1000 \mathrm{pmol} / 100 \mu \mathrm{l}$ were transferred to conical polyethylene centrifuge tubes $(1.5 \mathrm{ml})$ containing $20 \mathrm{mg}$ activated alumina, $50 \mathrm{pmol}$ dihydroxybenzylamine (internal standard) in $50 \mu \mathrm{l} 0.2 \mathrm{M}$-perchloric acid and $1 \mathrm{ml} 1 \mathrm{M}$-Tris$\mathrm{HCl}$ buffer ( $\mathrm{pH} \mathrm{8.9)}$. To allow complete adsorption of catechols to the alumina the tubes were vortexed for $20 \mathrm{~min}$ and then centrifuged for $1 \mathrm{~min}$ at $8000 \mathrm{~g}$. The supernatants were aspirated and after resuspending the alumina particles in $1.5 \mathrm{ml}$ distilled water the tubes were centrifuged for 1 min at $8000 \mathrm{~g}$. The washing procedure was repeated and after aspirating each tube thoroughly 200 $\mu \mathrm{l} 0.2 \mathrm{M}$-perchloric acid were added to desorb the catechols and the tubes stored at $-80^{\circ} \mathrm{C}$ until required. Approximate recovery values for dopamine, noradrenaline and adrenaline in the alumina extraction were 75,80 and $83 \%$ respectively. After centrifugation for $1 \mathrm{~min}$ at $8000 \mathrm{~g}, 100 \mu \mathrm{l}$ supernatant were injected onto an Altex Ultrasphere ODS column $(250 \times 4.6 \mathrm{~mm})$ and eluted with a mobile phase which consisted of $0.05 \mathrm{~mol}$ sodium acetate $/ 1,0.01 \mathrm{~mol}$ citric acid $/ 1,0.13 \mathrm{mmol}$ ethylenediamine tetra acetic acid/l, $0.43 \mathrm{mmol}$ sodium octyl sulphate $/ 1$ and $15 \%(\mathrm{v} / \mathrm{v})$ methanol (flow rate $1.2 \mathrm{ml} / \mathrm{min}$ ). The carbon/oil paste working electrode of the electrochemical detector (LC3A, Bioanalytical Systems, IN, U.S.A.) was maintained at $+0.75 \mathrm{~V}$ relative to a silver/silver chloride reference electrode. The retention times for noradrenaline, adrenaline, dihydroxybenzylamine and dopamine were $6 \cdot 0,7 \cdot 5,9.5$ and $14.0 \mathrm{~min}$ respectively. Since an equal amount of the internal standard, dihydroxybenzylamine, was added to the tissue samples and external catecholamine standards, the height of the dihydroxybenzylamine peak was used to correct for any variations in the recovery of the three catecholamines. The accuracy of the overall assay procedure was thus assured. The concentrations of dopamine, noradrenaline and adrenaline were calculated from their respective standard curves by linear interpolation. On the basis of repeated estimates of the catecholamine content of 3 separate pooled samples, the coefficient of assay variation was $<6 \%$ for each catecholamine.

\section{Results}

Since only a single terminal blood sample was withdrawn from each of the 84 hens killed for determination of hypothalamic LHRH and catecholamine concentrations, a comparison was made between the concentrations of LH in these plasma samples and in those from a group of 5 hens sampled at $2-\mathrm{h}$ intervals for $24 \mathrm{~h}$ around the time of ovulation of their first egg of a sequence. As shown in Text-fig. 1(c) comparable patterns of $\mathrm{LH}$ secretion were observed in the two groups of hens with the preovulatory rise in LH starting 6-8 $\mathrm{h}$ before the expected time of ovulation and reaching a peak $4-5 \mathrm{~h}$ before the expected time of ovulation. The occurrence of ovulation at the expected time was subsequently confirmed for the 5 hens not killed in the study by reference to their oviposition records.

The concentrations of LHRH in the PH-me and AH-POR during the course of the 28-h sampling period are shown in Text-figs 1 (a) and 1(b), respectively. One-way analyses of variance revealed significant $(P<0.01)$ fluctuations in the LHRH content of both regions with the lowest 


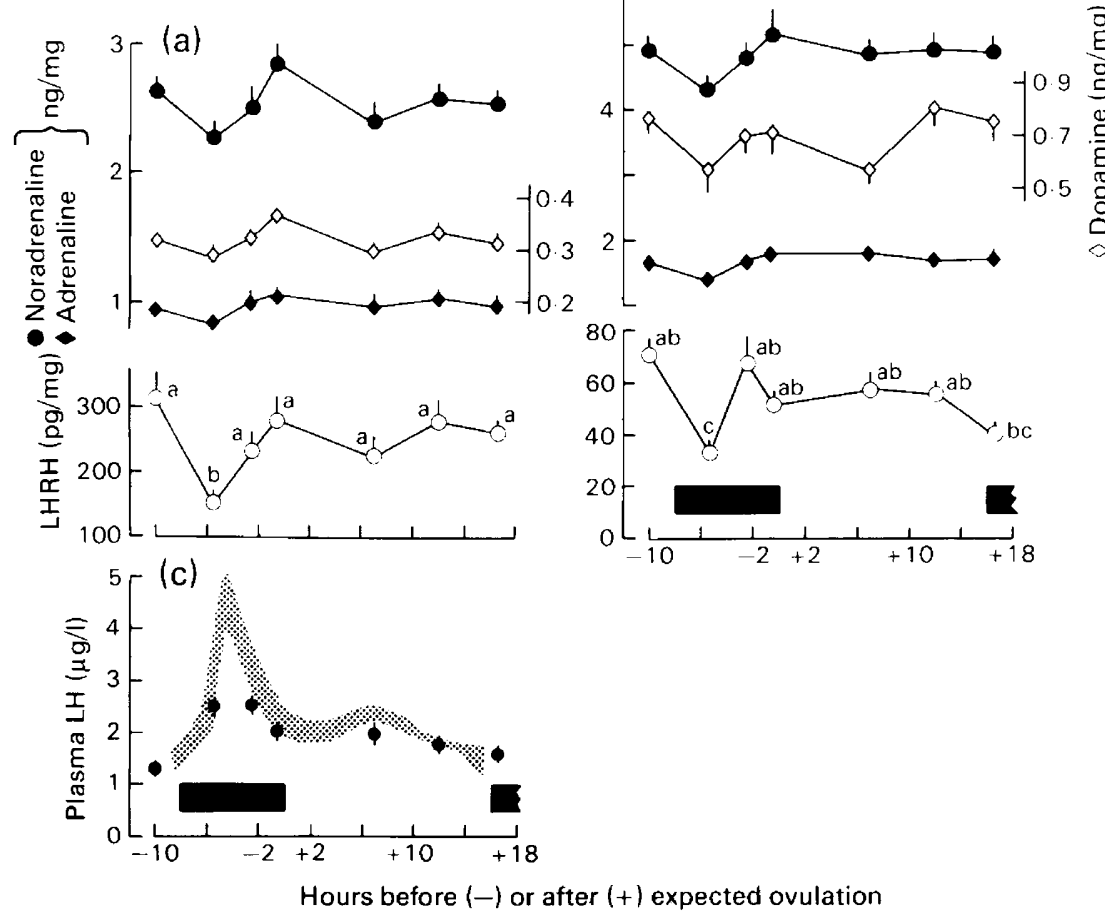

Text-fig. 1. Concentrations (means \pm s.e.m. $n=12$ ) of noradrenaline ( $)$ ), dopamine $(\diamond)$, adrenaline ( $\bullet$ ) and LHRH in (a) posterior hypothalamus-median eminence and (b) anterior hypothalamus-preoptic region and (c) of LH in plasma of hens killed at different times before or after the expected time of ovulation. In (c) the hatched area represents the plasma LH profile (mean \pm s.e.m.) of a group of 5 hens sampled at 2-h intervals for $24 \mathrm{~h}$. The black horizontal bar indicates the period of darkness. Means without a common letter are significantly different at the $1 \%$ level of probability (analysis of variance followed by Students $t$ test when a significant $F$ ratio was obtained).

concentration in hens killed $1 \mathrm{~h}$ before the peak of the preovulatory surge of LH. An apparent inverse relationship existed between plasma LH and hypothalamic LHRH around the time of the preovulatory LH surge. The ascending slope of the LH surge was associated with a dramatic $50 \%$ fall in the concentration of LHRH in both the PH-me (from $316 \pm 41$ to $152 \pm 19 \mathrm{pg} / \mathrm{mg} ; P<$ 0.01 ) and AH - POR (from $70.7 \pm 7.4$ to $33.0 \pm 5.1 \mathrm{pg} / \mathrm{mg} ; P<0.01$ ) while the subsequent decline in plasma LH was associated with a significant $(P<0.01)$ rise in LHRH in both regions to levels comparable with those before the preovulatory LH surge.

Although one-way analyses of variance did not reveal any significant fluctuations in the concentrations of noradrenaline, adrenaline or dopamine throughout the ovulatory cycle, a striking feature of these data was the apparent correlation between the concentrations of the three catecholamines and of LHRH (Text-fig. 1). Intra-individual correlation analyses of the data established that in the PH-me $(n=84)$ the concentrations of LHRH were significantly correlated with those of noradrenaline $(r=0.443 ; P<0.001)$, adrenaline $(r=0.302 ; P<0.01)$ and dopamine $(r=0.553 ; P<0.001)$. In the AH-POR $(n=84)$, however, the concentrations of LHRH were correlated with those of noradrenaline $(r=0.252 ; P<0.05)$ and adrenaline $(r=$ $0.233 ; P<0.05)$ but not with those of dopamine $(r=0.166 ; P>0.05)$. 


\section{Discussion}

Several observations suggest that a release of LHRH from the median eminence is a prerequisite for the preovulatory release of LH in the hen. Premature ovulation can be induced by injection of synthetic ovine LHRH (van Tienhoven \& Schally, 1972) and both spontaneous and progesteroneinduced ovulation can be blocked by passive immunization with antibodies raised against LHRH (Fraser \& Sharp, 1978). Furthermore, in contrast to the rat (Aiyer, Fink \& Greig, 1974), the responsiveness of the anterior pituitary gland to LHRH does not appear to increase at the time of the preovulatory LH surge in the hen (Bonney, Cunningham \& Furr, 1974). It is likely, therefore, that the fall in the hypothalamic content of LHRH observed at the time of the preovulatory LH surge in the present study reflects a depletion of stored LHRH resulting from a transient hypersecretion of LHRH rather than a decline in LHRH synthesis. This observation in the hen is consistent with a number of reports of alterations in hypothalamic LHRH content during the oestrous cycle of the rat. Studies involving bioassay (Chowers \& McCann, 1965; Ramirez \& Sawyer, 1966) and radioimmunoassay (Kalra \& Kalra, 1977; Barr \& Barraclough, 1978; Oshima, Morishita, Omura \& Saito, 1978; Wise, Rance, Selmanoff \& Barraclough, 1981) of LHRH have revealed a fall in hypothalamic content between the morning and afternoon of pro-oestrus, at the time of the preovulatory release of gonadotrophins. Furthermore, analysis of hypophysial portal blood collected from anaesthetized rats at different stages of the oestrous cycle (Sarkar, Chiappa \& Fink, 1976) has confirmed that an enhanced release of LHRH into the portal circulation occurs at this time. Whilst a causal relationship between the fall in hypothalamic LHRH content and the preovulatory rise in plasma LH observed in the present study seems likely, the possibility cannot yet be excluded that the fall in LHRH content reflects a diurnal alteration in hypothalamic activity. Indeed, in agreement with an earlier report (Harrison, Casey, Adair \& Reeves, 1974) of higher LHRH-like biological activity in the hypothalamus of hens during the light phase than during the dark phase, the fall in LHRH in the present study coincided with the onset of darkness. However, in hens maintained on a regular light : dark cycle (e.g. $16 \mathrm{~h}$ light : $8 \mathrm{~h}$ darkness as in this study) preovulatory surges of $\mathrm{LH}$ are in any case restricted to an approximate 8-h period starting shortly after the onset of darkness. The resolution of this uncertainty must await the analysis of daily fluctuations in hypothalamic LHRH content in hens about to lay their final egg of a sequence (i.e. on a day when ovulation does not occur).

The suppressive effects of hypothalamic lesions on spontaneous and progesterone-induced ovulation in the hen (Ralph, 1959; Ralph \& Fraps, 1959) can now be attributed to their disruptive influence on LHRH neurones, the intrahypothalamic distribution of which has been established using immunocytochemical methods (Sterling \& Sharp, 1982): the LHRH content of the PH-me (which contains most of the immunopositive LHRH terminals) was approximately 5 times greater than that of the AH-POR (which contains most of the immunoreactive LHRH cell bodies). The present observation that the LHRH content of the AH-POR and PH-me declined at the time of the preovulatory LH surge is perhaps surprising, therefore, since the releasable pool of LHRH would presumably be confined to secretory granules in the nerve terminals of the median eminence. However, as immunoreactive LHRH is widely distributed in fowl hypothalamus and indeed in other extra-hypothalamic loci (Knight et al., 1983) it is possible that the fall in the LHRH content of the AH-POR was the result of an enhanced release of LHRH from a diffuse network of LHRH terminals throughout the region. A comparable situation may exist in the rat since Wise et al. (1981) reported simultaneous alterations in the LHRH content of anteriorly and posteriorly located hypothalamic loci during pro-oestrus.

Although no statistically significant fluctuations in the steady-state concentrations of catecholamines in the AH-POR or PH-me were detected during the ovulatory cycle, these data were nevertheless indicative of a role of catecholamines in modulating LHRH neuronal activity since the concentrations of LHRH were significantly correlated with those of noradrenaline, adrenaline and dopamine. In the AH-POR and PH-me the preovulatory fall in LHRH content was accompanied 
by simultaneous reductions in the mean concentrations of dopamine, noradrenaline and adrenaline. Similarly, the subsequent rise in LHRH content was accompanied by a rise in the mean concentration of each catecholamine. Evidence from pharmacological studies in hens (van Tienhoven, Nalbandov \& Norton, 1954; Knight et al., 1982b) suggests the participation of a facilitatory $\alpha$-adrenergic system in the preovulatory $\mathrm{LH}$ release mechanism and in this respect the hen appears to be similar to mammals (Sawyer, 1979). In contrast with the present indication of a preovulatory fall in hypothalamic catecholamine content in the hen, we have previously observed that the progesterone-induced release of $\mathrm{LH}$ in the hen is accompanied by a rise in hypothalamic catecholamine levels (Knight, Francis, Holman \& Gladwell, 1982a). Similarly, in rats, the noradrenaline content of the anterior hypothalamus reportedly increases during pro-oestrus when the preovulatory release of LH occurs (Stefano \& Donoso, 1967; Selmanoff, Pramik-Holdaway \& Weiner, 1976). According to Crowley, O’Donohue \& Jackobowitz (1978), however, the noradrenaline and dopamine content of the preoptic region is reduced during pro-oestrus and oestrus compared with other days of the cycle. The interpretation of such observations can seldom be more than speculative since fluctuations in steady-state catecholamine levels may reflect alterations in the synthesis, storage, release and/or reuptake of transmitter. Whilst we do not yet have any information on the turnover rates of catecholamines in the hen hypothalamus throughout the ovulatory cycle, in view of the above-mentioned pharmacological evidence for a facilitatory $\alpha$-adrenergic involvement, it is tempting to attribute the apparent preovulatory fall in hypothalamic catecholamine content in the hen to a transient increase in catecholaminergic activity at this time. A difficulty arises with this interpretation, however, as there is also pharmacological evidence for the involvement of an inhibitory dopaminergic pathway in the $\mathrm{LH}$ release mechanism in the hen (Hibbs, Gladwell \& Cunningham, 1977; Knight et al., 1982b) and the rat (Drouva \& Gallo, 1977; see Weiner \& Ganong, 1978).

The observation that the levels of all 3 catecholamines appeared to change in synchrony during the course of the sampling period suggests that the 3 catecholamines may coexist within the same population of neurones and so much of the dopamine present in the hypothalamus may merely function as an intermediary substance in the biosynthesis of noradrenaline and adrenaline rather than as a neurotransmitter per se. It is anticipated that the future application of immunocytochemical techniques employing antibodies directed against the various enzymes involved in catecholamine biosynthesis (see Fuxe et al., 1978) to the study of the aminergic innervation of the fowl hypothalamus will permit resolution of these uncertainties.

We thank Professor T. R. Morris for provision of facilities at Lane End Farm, Shinfield, Reading and Dr S. Lynch for the supply of LHRH antiserum. This work was supported by the Agricultural Research Council (Grant 45/189).

\section{References}

Aiyer, M.S., Fink, G. \& Greig, F. (1974) Changes in the sensitivity of the pituitary gland to luteinizing hormone releasing factor during the oestrous cycle of the rat. $J$. Endocr. 60, 47-64.

Barr, G.D. \& Barraclough, C.A. (1978) Temporal changes in medial basal hypothalamic LH-RH correlated with plasma LH during the rat estrous cycle and following electrochemical stimulation of the medial preoptic area in pentobarbital-treated proestrous rats. Brain Res. 148, 413-423.

Bonney, R.C., Cunningham, F.J. \& Furr, B.J.A. (1974) Effect of synthetic luteinizing hormone releasing hormone on plasma luteinizing hormone in the female domestic fowl, Gallus domesticus. J. Endocr. 63, 539-547.

Buonomo, F.C., Rabii, J. \& Scanes, C.G. (1981) Aminergic involvement in the control of luteinizing hormone secretion in the domestic fowl. Gen. comp. Endocr. 45, 162-166.
Chowers, I. \& McCann, S.M. (1965) Content of LHRF and $\mathrm{LH}$ during the estrous cycle and after changes in gonadal steroid titers. Endocrinology 76, 700-708.

Crowley, W.R., O'Donohue, T.L. \& Jacobowitz, D.M. (1978) Changes in catecholamine content in discrete brain nuclei during the estrous cycle of the rat. Brain Res. 147, 315-326.

Drouva, S.V. \& Gallo, R.V. (1977) Further evidence for inhibition of luteinizing hormone release in ovariectomized rats by stimulation of dopamine receptors. Endocrinology 100, 792-798.

El Halawani, M.E., Burke, W.H. \& Ogren, L.A. (1980) Involvement of catecholaminergic mechanisms in the photoperiodically induced rise in serum luteinizing hormone of Japanese quail (Coturnix coturnix japonica). Gen. comp. Endocr. 41, 14-21.

Follett, B.K., Scanes, C.G. \& Cunningham, F.J. (1972) A radioimmunoassay for avian luteinizing hormone. $J$. Endocr. 52, 359-378. 
Fraps, R.M. (1965) Twenty-four hour periodicity in the mechanism of pituitary gonadotropin release for follicular maturation and ovulation in the chicken. Endocrinology 77, 5-18.

Fraps, R.M. \& Dury, A. (1943) Occurrence of premature ovulation in the domestic fowl following administration of progesterone. Proc. Soc. exp. Biol. Med. 52, 346-349.

Fraser, H.M. \& Sharp, P.J. (1978) Prevention of positive feedback in the hen (Gallus domesticus) by antibodies to luteinizing hormone releasing hormone. $J$. Endocr. 76, 181-182.

Furr, B.J.A., Bonney, R.C., England, R.J. \& Cunningham, F.J. (1973) Luteinizing hormone and progesterone in peripheral blood during the ovulatory cycle of the hen, Gallus domesticus. J. Endocr. 57, 159-169.

Furr, B.J.A. \& Smith, G.K. (1975) Effects of antisera against gonadal steroids on ovulation in the hen, Gallus domesticus. J. Endocr. 66, 303-304.

Fuxe, K., Hokfelt, T., Agnati, L.F., Johansson, O., Goldstein, M., Perez de la Mora, M., Possani, L., Tapia, R., Teran, L. \& Palacios, R. (1978) Mapping out central catecholamine neurones: immunohistochemical studies on catecholamine-synthesizing enzymes. In Psychopharmacology, a Generation of Progress, pp. 39-66. Eds M. A. Lipton, A. DiMascio \& K. F. Killam. Raven Press, New York.

Harrison, P.C., Casey, J.M., Adair, R.L. \& Reeves, J.J. (1974) Fluctuation of hypothalamic luteinizing hormone releasing hormone and pituitary gonadotropins in laying and non-laying hens. Poultry Sci. 53, 554 559.

Hibbs, M., Gladwell, R.T. \& Cunningham, F.J. (1977) Effect of the intraventricular administration of dopamine on plasma luteinizing hormone concentration in the domestic fowl. $J$. Endocr. 75, $43 P$.

Kalra, P.S. \& Kalra, S.P. (1977) Temporal changes in the hypothalamic and serum luteinizing hormone-releasing hormone (LH-RH) levels and the circulating ovarian steroids during the rat oestrous cycle. Acta endocr., Copenh. 85, 449-455.

Knight, P.G., Francis, P.T., Holman, R.B. \& Gladwell, R.T. (1982a) Changes in hypothalamic monoamine concentrations accompany the progesterone-induced release of luteinizing hormone in the domestic hen. Neuroendocrinology 35, 359-362.

Knight, P.G., Wilson, S.C., Gladwell, R.T. \& Cunningham, F.J. (1982b) Evidence for the involvement of central catecholaminergic mechanisms in mediating the preovulatory surge of luteinizing hormone in the domestic hen. J. Endocr. 94, 295-304.

Knight, P.G., Cunningham, F.J. \& Gladwell, R.T. (1983) Concentrations of immunoreactive luteinizing hormone releasing hormone in discrete brain regions of the cockerel: effects of castration and testosterone replacement therapy. $J$. Endocr. 96, 471-480.

Mefford, I.N., Gilberg, M. \& Barchas, J.D. (1980) Simultaneous determination of catecholamines and unconjugated 3,4-dihydroxyphenylacetic acid in brain tissue by ion-pairing reverse-phase high performance liquid chromatography with electrochemical detection. Analyt. Biochem. 104, 469-472.

Meites, J. \& Sonntag, W. E. (1981) Hypothalamic hypophysiotrophic hormones and neurotransmitter regulation: current views. Ann. Rev. Pharmacol. Toxicol. 21, 295-322.

Oshima, I., Morishita, H., Omura, K., \& Saito, S. (1978) Changes in hypothalamic LH-RH content and blood levels of $\mathrm{LH}-\mathrm{RH}$, gonadotrophin and oestradiol during the preovulatory stage of rat oestrous cycle. Endocr. Jap. 25, 607-611.

Ralph, C.L. (1959) Some effects of hypothalamic lesions on gonadotrophin release in the hen. Anat. Rec. 134, 411-431.

Ralph, C.L. \& Fraps, R.M. (1959) Effect of hypothalamic lesions on progesterone induced ovulation in the hen. Endocrinology 65, 819-824.

Ramirez, V.D. \& Sawyer, C.H. (1966) Fluctuation in hypothalamic LHRH during the rat estrous cycle. Endocrinology 76, 282-289.

Sarkar, D.K., Chiappa, S.A. \& Fink, G. (1976) Gonadotrophin releasing hormone surge in pro-oestrous rats. Nature, Lond. 264, 461-463.

Sawyer, C.H. (1979) Brain amines and pituitary gonadotrophin secretion. Can. J. Physiol. Pharmacol. 57, $667-680$.

Selmanoff, M.K., Pramik-Holdaway, M.J. \& Weiner, R.I. (1976) Concentrations of dopamine and norepinephrine in discrete hypothalamic nuclei during the rat estrous cycle. Endocrinology 99, 326-329.

Stefano, F.J.E. \& Donoso, A.O. (1967) Norepinephrine levels in the rat hypothalamus during the estrous cycle. Endocrinology 81, 1405-1406.

Sterling, R.J. \& Sharp, P.J. (1982) The localization of LH-RH neurones in the diencephalon of the domestic hen. Cell Tiss. Res. 222, 283-298.

van Tienhoven, A. \& Schally, A.V. (1972) Mammalian luteinizing hormone releasing hormone induces ovulation in the domestic fowl. Gen. comp. Endocr. 19, 594-595.

van Tienhoven, A., Nalbandov, A.V. \& Norton, H.W. (1954) Effect of dibenamine on progesterone-induced and 'spontaneous' ovulation in the hen. Endocrinology 54, 605-611.

Warren, D.C. \& Scott, H.M. (1935) The time factor in egg formation. Poultry Sci. 14, 195-207.

Weiner, R.I. \& Ganong, W. F. (1978) The role of brain amines and histamine in regulation of anterior pituitary secretion. Physiol. Rev. 58, 905-976.

Wilson, S.C. \& Cunningham, F.J. (1980) Modification by metyrapone of the 'open period' for pre-ovulatory LH release in the hen. Br. Poultry Sci. 21, 351-361.

Wilson, S.C. \& Sharp, P.J. (1973) Variations in plasma LH levels during the ovulatory cycle of the hen, Gallus domesticus. J. Reprod. Fert. 35, 561-564.

Wilson, S.C. \& Sharp, P.J. (1975) Changes in plasma concentrations of luteinizing hormone after injection of progesterone at various times during the ovulatory cycle of the domestic hen (Gallus domesticus). $J$. Endocr. 67, 59-70.

Wise, P.M., Rance, N., Selmanoff, M. \& Barraclough, C.A. (1981) Changes in radioimmunoassayable luteinizing hormone-releasing hormone in discrete brain areas of the rat at various times on proestrus, diestrus day 1 and after phenobarbital administration. Endocrinology 108, 2179-2185.

Received 17 October 1983 